\title{
Yin Yang: A New Perspective in Understanding the Development of Religion in Contemporary China
}

\author{
CHU YI, Lu \\ Brigham Young University, USA
}

\begin{abstract}
The Taoism on Yin Yang has influenced the Orientalists’ perception concerning the types of relation among all existence in the universe for centuries. It maintains that a society is comprised of countless antagonistic components or conflicting social players, including religious institutions and the Chinese government. All existence is charged with two great forces, simply known as Yin and Yang. These two great forces are opposite-but-complementary to each other. They determine how social players interact to avoid chaos and destructions, so balance and harmony are established and maintained in society. In other words, Yin Yang helps the social players to form a harmonious relationship with one and another by weakening or strengthening their inner inherited Yin-or-Yang elements according to timing and conditions. Drawing on recent research on Yin Yang as a novel approach in understanding business-related issues in contemporary China, such concept is also relevant to understand the development of religion in China.
\end{abstract}

Keywords: religion, China, Taoism, Yin Yang

\section{Introduction}

The relationship between religion and the Chinese government has always been convoluted throughout Chinese history. Although religion has experienced extermination, rejection, and skepticism, but it has always been able to preserve itself from the confinement and suppression of the Chinese government. Their relationship can be perceived as a roller-coaster-ride - it has its ups and downs, but they cannot dissolve their bond regardless of how strongly the Chinese government believes that religion can be terminated in China. Therefore, what kind of magical force that appears to be covert and intangible has bound them together. In order to find answer to this question, the writer studied the pattern of historical religious movement in China and compared it with the observations and findings on the development of Christianity during the writer's recent fieldwork in Beijing, China. It is quite apparent that the relationship between religious institutions and the Chinese government is not absolutely vertically or hierarchically structured, instead, their relationships are complementary and interdependent just like the relationship between Yin and Yang in Daoist philosophy.

Therefore, in order to understand how religion has developed in Chinese Cultural Revolution, it is useful to apply the Yin Yang concept to analyze the relationship between religious institutions and the Chinese government. Despite the Yin-Yang concept is a philosophical one, this ultimate purpose of this study is

CHU YI, Lu, Department of Sociology, Brigham Young University.

Correspondence concerning this article should be addressed to Provo, Utah 84602-1001, United States. Email: Ms.2pm@live.com. 
sociological. It concerns with the critical but negligible role of Chinese culture that has played in influencing and determining the types of interactions and relationships between religious institutions and the Chinese government in China.

\section{Literature Review}

The Dao produces the One.

The One produces the Two.

The Two produces the Three.

The three produces All Things.

All Things carry Yin and hold to Yang.

Their blended influence brings Harmony.

This excerpt is taken from Dao De Jing (道德经), which briefly summarizes the Chinese philosophical understanding about the creation of the entire universe and its relationship with humans and the earth (Lee et al., 2008, p. 88; Fang, 2011, p. 33). There is no spirit or super force personified in Chinese religion or philosophy as there is in Buddhism, Christianity, and other worldly religions. Thus, the "One" mentioned in Dao De Jing is literally nameless.

According to Laozi, the founder of Dao De Jing, anything that can be described in words is not the One and the One is not a thing or a person, it is a path of changes (Cooper, 2010). If it has to be described in terminology, it is named the "Dao" (道) or the Way and which is defined in Dao De Jing as such:

As for the Way:

It is what the mouth cannot speak of,

The eyes cannot see,

And the ears cannot hear.

It is that which we cultivate the mind and align the body.

When people lose it they die;

When people gain it they flourish.

When endeavors lose it they fail;

When they gain it they succeed.

The Way never has a root or trunk,

It never has leaves or flowers.

The myriad things are generated by it;

The myriad things are completed by it.

We designate it 'the Way'. (Roth, 1999, p. 56)

The "Dao" is the origin or the natural course that brings everything into existence. The "Two" represents the dual charges or natures of reality, the Yin and Yang which are also known as the Two Great Forces. The "Three" suggests that the universe is composed of heaven, earth, and humans. Humans are thought to be the communicator and mediator between heaven and earth. Their interactions produce relationships and bring all things into existence (Lee et al., 2008; Fang, 2011). Nevertheless, this does not place humans as the measure of the universe. All existence is governed by the orders established by Nature. Men's responsibility, in Taoism, is to maintain the balance between all existence, physically, mentally, and spiritually (Cooper, 2010).

All existences and relationships inherit the dual natures of Yin Yang and they all have a purpose to fulfill. 
Their obligations can only be realized and become meaningful through Yin-Yang interaction. Theoretically speaking, the Yin-Yang forces exist paradoxically but are not irreconcilable: They complement each other to promote harmony and balance in the universe. As Cooper (2010)asserts:

They are the two sides of one coin. They are at one and the same time a divisions and reunion, and if they are spoken of as contending forces, they are also cooperating powers and the tension in which they are held is that of harmony, of the mutual play of creation, not of conflict. There is no Creator in Taoism, but the operation of the Tao brings about a spontaneous creation through the interaction of the Yin and the Yang (p. 19-20).

When the two-opposite-but-complementary forces form harmonious relationships in accordance with the natural course of "Dao", all existences can achieve transcendence through coexistence and interdependence with one another. Although how "transcendence" can be achieved was never explicitly discussed in Daoist philosophy, there were many Daoist myths about how ordinary humans overcame their shortcomings through various paths and eventually became "one" (harmony) with the "Dao" and obtained immortality to become “Xian” (仙) or immortals. Applying the idea of human transcendence to contextualize nonhuman existences, they may find that the general idea of transcendence permits all things to perpetuate their current existences by uplifting them to higher standards.

Taoism emphasizes on moderation and harmony. When the interactions between Yin and Yang violate the natural course of "Dao", conflicts, disagreements, and compulsions are likely to incur. In real life, they are taught to shun away from conflicts and disagreements, but Daoism sees catastrophes or disorders as ineluctable parts of reality and argues that they offer good opportunities to resolve some conflicts or even produce growth from creating new and altered interactions. Sometimes failures may even provide propitious conditions in which other phenomena can thrive or regenerate.

Daoist philosophy perceives the world as "holistic, dynamic, and dialectical” (Fang, 2011; Chen, 2002; Li, 1998; Peng \& Nisbett, 1999). Many sociologists derive in conclusion that Chinese culture and society have been influenced by the combination of Chinese indigenous beliefs and the "three teachings" of Confucianism, Daoism, and Buddhism (Bell, 1989; Yang, 1976). For this reason, Chinese society accepts the practice of polytheism and worshiping multiple deities at once despite religions and philosophies have faced Chinese rejection and persecution, often from the government. Instances include the burning of books and burying of Confucian scholars during Qin Dynasty between 213 and 210 B.C. and the complete ban of religious activities and practices during the Chinese Cultural Revolution from 1967 to 1977. The Chinese culture, nonetheless, under the influence of the dual-thinking of Yin Yang, has typically tolerated the mutual existence of distinct belief systems.

Daoist scholars recognize the universality of the Yin-Yang concept in understanding the world around them, “...it has influenced Chinese philosophies, martial arts, medicine, science, literature, politics, daily behavior, religious beliefs, thinking, and other fields for thousands of years” (Fang, 2011, p. 33). Scholars emphasize that Yin-Yang thinking is more than simply a part of Chinese culture. In fact, their opposing nature has been directly reflected by the impact of two most influential Chinese traditional philosophies (Confucianism and Daoism) on Chinese traditional life and the social structure. Fritjof (1975) points out, "Confucianism was rational, masculine, active and dominating. Taoism, on the other hand, emphasized all that was intuitive, feminine, mystical, and yielding” (p. 130). The notion of division of labor between Confucianism and Daoism to achieve harmony and transcendence in Chinese society has much been influenced by the 
concept of Yin-Yang interaction. In order to bring all relationships into existence, the Yin and Yang elements must be present. Confucianism, under the influence of Yang, has given shape to Chinese political and social structure by playing a prominent and hegemonic role in Chinese society throughout the years. In order to be able to respond and interact with the Yang-dominated Chinese political atmosphere, the rest of the social institutions including religion have adapted the Yin characters.

With respect to this important concept, Taoist approach provides an alternative view in understanding the relationship that has developed between religion and the Chinese state authority over the years. Instead of viewing them from a traditional or a "fearful" perspective, which suggests that religion is an inferior subject to Chinese government rulings due to the indelible impressions that were left by the impact of Chinese Cultural Revolution of the 60s, the alternative perspective suggests that the religious institutions in contemporary China have gradually obtained more legal status, persistence, and power through the mythical influence of Yin-Yang interaction. In fact, the Yin-Yang interaction not only draw religion and the Chinese authority closer to form a symbiotic relationship, but their interaction also encourages religion to transcend in Chinese society by increasing its impact and growing in sizes at the Chinese community level.

\section{Yin and Yang}

Taoism has been the second most influential philosophy throughout Chinese history. It borrowed the Yin-Yang notion of opposite-but-complementary characteristics in explaining relationships and the role of humanity in relation to heaven and earth. It posits that all phenomena and all relationships come naturally in pairs of opposites such as heaven and earth, day and night, joy and dejection, winter and summer, male and female, movement and stasis. They are opposite-but-complementary because nothing is dominated entirely by Yin or Yang, but rather, these two opposing forces are both present within phenomena for interaction with other phenomena. However, the amount of Yin and Yang that phenomena carry is determined by the types of roles, relationships, and interaction that they have with others in the universe. Moreover, the Yin-Yang elements within a phenomenon are gradually transformed and shifted through interaction over time. When a predominant-Yin phenomenon interacts with a predominant-Yang phenomenon, their interaction will bring out or strengthen the embedded Yang within the predominant-Yin and enervate the predominant-Yang of another phenomenon to cultivate its hidden Yin. A simple example of Yin-Yang interaction is the phenomenon of changing temperatures throughout the day and night which brings significant seasonal changes throughout the year. In Daoist perspective no phenomenon is static or exists without being interrelated or interdependent to each other.

\section{The Yin-Yang Symbol}

Most people have seen the symbol of Yin-Yang. It is a circle that is made up by a black and a white swirl; the whole circle denotes eternity. Although the Yin-Yang symbol is not evenly bisected in the middle of the circle, it is carved evenly in halves. The two nicely carved swirls represent the dynamic motion of Yin-Yang interaction. They interchange their opposite energies to cultivate and uncover their hidden forces.

\section{The Yin}

Yin is often represented in the black portion of the circle, and it is less prominent comparing to Yang. In Chinese culture, "Yin is everything that is esoteric" (Fowler \& Fowler, 2008, p. 50). The feminine essence is 
usually associated with Yin because of her gentleness, beauty, docility, submissiveness, and fragility. However, Yin does not represent weakness; it is simply another form of strength which endures and remains steadfast to the counteractive force of Yang (Fowler \& Jeaneane, 2008). The 18th-century Taoist Liu Yiming described the characteristics of Yin in terms of a person, an explanation that is appropriate in defining the role and status of religion in China:

Flexibility is docility, yielding, self-mastery, self-restraint, self-effacement, humility, selflessness, consideration of others, absence of arbitrariness, pure simplicity, genuineness. Those who use flexibility well appear to lack what they are in fact endowed with, which appears to be empty when they are in fact fulfilled. They do not take revenge when offended. They seek spiritual riches and are aloof of mundane riches; they do not contend with people of the world (Olson, Stuart Alve, 2001; Fowler \&Jeaneane, 2008).

These characteristics of Yin are applicable to the nature and the development of religion in China, especially to those religious organizations that are non-affiliated with the five Chinese Constitution sanctioned religions - Buddhism, Catholicism, Islam, Protestantism, and Daoism. These religious organizations have to utilize the Yin-elements to organize stealthily and flexibly in accordance with the often-changing Chinese policies of Chinese government.

According to Daoist philosophy, the role and the status of religion are predominantly governed by the Yin elements. The nature of Yin has equipped religion in China with flexible, yielding, esoteric, and persistent characteristics for dealing with the peremptory and aggressive Chinese cult. For instance, in ancient China, the malleability of Yin helped all the imported religions - Buddhism, Christianity, and Islam - to transform and adjust the focus of their religious precepts and practices to ease integration into the state-regulated Chinese traditional society. No matter how gruesome and brutal the cultural and political climate was, once the seeds of religion were planted in Chinese soil, they quickly became rooted and gradually became indispensable parts of Chinese cultural heritage. Persistence, another characteristic of Yin, taught religion to be submissive in times of crisis and solidary when faced with the state's suppression.

The nature of Yin does not encourage religion to confront the Chinese authority in a hard and rigid manner. One of the Chinese famous proverbs stems from the Yin-Yang interaction which means to implement softness and flexibility to counterbalance its oppositional forces such as durability and firmness. This proverb is usually associated with one of Chinese Kong Fu styles; utilizing "soft" power to fight against the adamant or "hard" power. Doing so not only will result in less injury to oneself but will also outstrip one’s component's hard power by taking the lead. This is also the reason why Chinese philosophy emphasizes greatly on how powerful the water can carry the soft power that eventually breaks down the hard power of rocks.

If they apply this concept to analyze the role and the status of religion in China, they shall find similar results even though these results are not immediately noticeable. It takes time for the soft power of religion to obtain legal status through interaction with the hard power of Chinese authority. Consequently, in time of urgency or danger, Daoist philosophy asserts that the Yin-inherited targets should remain submissive and even dormant if necessary. For example, religion's docility and willingness to remain dormant during the Chinese Cultural Revolution between 1967 and 1977 protected religion from extermination even though religious individuals were harassed and humiliated by the Red Guards. After a decade of waiting, religious regeneration and reemergence were possible after Mao's death in 1976. It was a favorable time for religion to revive and regain strength. Since then, many religious institutions have awakened according to their inherit Yin nature and reemerged at the Chinese societal surface, cautiously and gradually expanding their efforts 
throughout China.

\section{The Yang}

In contrast to Yin, Daoism defines Yang as powerful and as radiant as the sun. It portrays the characteristics of masculinity and denotes energy and vitality of life. "It is aggressive, hard, heat, dryness, the bone of the body, the hard, dry stone of the home, the south, sunny side of a valley or river bank, and the spring and summer time of the year” (Fowler \& Jeaneane, 2008, p. 50). Most importantly, Yin and Yang together they form a great pair; without them we cannot know what goodness is without knowing what evil is.

Historically, the Chinese state has been influenced by both Confucian and Western thought. According to Max Weber and other scholars, the structure and organization of ancient Chinese society reflected the influence of Confucianism. As Confucianism was the most popular philosophy, with "a long tradition of involvement in political construction” (Eberlein, 2008), and Confucian thought persisted for many centuries. The present Chinese cult has inherited the Yang-principles in regulating and governing the Chinese society.

On the contrary, in Taoism, the government regulations, policies, and restrictions can be impediments to the Yin-Yang interactions between religion and the Chinese authority and directly hinder the proper development of Chinese society, because they are unnatural and artificial, altering the established orders by Nature.

Some Daoist adherents even argue that the government's excessive control often brings destruction and negative impact rather than positive influence on the government's relations with other social institutions and individuals. In this respect, the government's relationship to the religious institutions in China is imbalanced and underdeveloped at the national level due to the unjust interaction between religion's Yin and the Chinese authority's Yang. In order to achieve balance and harmony, the interaction between Yin and Yang must take place in accordance with the "Dao", without manipulation. The balance is the result of the occurrence of cyclical and never ending motions of transforming Yin from Yang and Yang from Yin. To maintain and perpetuate that balance neither of the Two Great Forces can dominate for an extended period of time (Ebrey, 1993). In fact, the natural balance or harmony is governed by the natural course of "Dao" which can be achieved by the idea of Wuwei (无为) or non-acting. Wuwei is "a kind of action that does not force things against their nature and is thus in accordance with the Dao" (Gentz, 2013, p. 79). When people stop imposing their desires and expectations on others, things develop in a spontaneous manner or Ziran (自然) which is propitious for the growth and transcendence of all phenomena (Moeller, 1893). The destruction of Ziran means that the balance between Yin and Yang is drastically destroyed or distorted which unleashes unrestrained amounts of Yang that cannot be counterbalanced by the impact of Yin, resulting in self-destruction.

The Chinese Cultural Revolution is a great example of the imbalanced interaction between Yin and Yang that slowly deteriorated the long-lived social orders and moral values of Chinese society in the 1960s. The Chinese government led by Mao stifled the different voices and belief systems in China and condemned the "Four Olds" - Old Customs, Old Culture, Old Habits, and Old Ideas — and eventually brought all other social institutions, such as schools, hospitals, religions, and factories to a standstill. The consequences that China has to face today are beyond reconstructing public facilities, restoring social institutions, and resuming daily activities. The loss of many Chinese morals, cultural, and traditional values has led to increasing social problems and social tension in China today. 


\section{The Yin-Yang Interaction}

“According to the Yin-Yang principles, all universal phenomena are shaped by the integration of two opposite cosmic energies, namely Yin and Yang” (Fang, 2011, p. 31). Although Yin and Yang are two opposite energies or forces, they are not designed to destroy or eliminate each other. Instead, they complement and reinforce each other by giving rise to their opposing forces that are hidden within their interaction. Ji, Nisbett, and Su (2001) described the codependency between Yin and Yang, as quoted by Fang (2011) : "When Yin reaches its extreme, it becomes Yang; when Yang reaches its extreme, it becomes Yin. The pure Yin is hidden in Yang, and the pure Yang is hidden in Yin” (p. 34). As a result, all phenomena must incorporate interdependent relationships, allowing their inherited Yin-Yang elements to be mutually dependent. As Fang (2006) explained:

Yin and Yang cannot survive without each other; they do not only complement each other, but they also depend on each other, exist in each other, give birth to each other, and succeed each other at different points in time. Yin and Yang, water and fire, the moon and the sun, and so forth, are waning and waxing, coming and going, opening and closing, all in the process of ceaseless change and transformation (p. 77).

In Taoism, the interactions between Yin-Yang forces, theoretically speaking, are "equally” powerful and insignificant. All that exists should manifest an equal weight of importance and insignificance.

However, maintaining harmonious relationships among all phenomena is a challenge, because nothing is entirely natural and free from human intervention. All phenomena need to be in accordance with the natural course of "Dao" and constantly going through conversion and facing changes through interactions, but their inherited Yin-Yang elements can be disturbed and imbalanced by humans' desires and interventions. Therefore, the outcomes of all existences and the consequences of relationships do not occur in a "situation-free, context-free, or time-free construct” (Fang, 2011).

\section{The Traditional View of the Relationship between Religion and the Chinese Authority}

From a traditional approach, the relationship between religion and the Chinese authority, under the impact of Confucianism and Western thinking, is unequal, hierarchical, and oppressed. Many scholars and religious activists argue that religion in modern China sometimes faces the Chinese government's inexplicable limitations and unpredictable harassments due to government's fear of the uncontrollable rise of religious organizations that may pose a threat to its political legitimacy. According to the U.S. State Department's International Religious Freedom Report of 2010 to 2012, there was only slight increase of religious freedom in China over that period. In fact, the Chinese government continues to keep religion on a tight leash by giving the United Front Department of the Chinese Communist Party (particularly the Second Bureau) and the State Administration for Religious Affair (SARA) unchecked power to regulate current religious affairs, control the distribution of religious materials, and inspect foreign religious materials coming into China (Kuo, 2011).

Based on this report, the traditional approach is partially correct in arguing that religion in contemporary China is placed at an inferior position because, historically, religion had always depended upon the endorsement or acceptance of Chinese rulers or Chinese government to thrive. In other words, religion in China was never a private or authoritative social organization in comparison to its counterparts in Western society. Sometimes, the Chinese government even borrowed religious beliefs and ideas for their advantage to monitor the life of Chinese people and keep society in order. For instance, the idea of Tian (heaven) and Tianzi (the son 
of heaven) were prevailing concepts that established the hierarchical structure of Chinese traditional society and reinforced the Chinese emperor's position, and legitimizing his rule as the only son of "heaven".

In addition, due to the increasing social problems and tensions deriving from the rapid economic development of Deng's Open Door policy, in recent years the Chinese central government has found religion to be a powerful tool in resolving ongoing social tensions in Chinese society. According to Kuo's (2011) current field research on Christianity in China,

"Peasants become more interested in religion in order to seek comfort amid untamed weather conditions and fluctuating agricultural prices. Workers, particularly migrant workers, find spiritual and material help in urban religious organizations. Entrepreneurs pray for windfall profits from business transactions. Even public officials look for spiritual guidance and blessing from religious leaders in order to gain a quick promotion, or to avoid getting caught for their corruption. Especially, "when natural disasters hit, the CCP state finds it efficient to enlist religious organizations to assist in human and financial rescue” (p. 1046-1047).

Therefore, in recent years the increasing religious influence at the community level has gradually reshaped and readjusted the relationships between religious institutions and the Chinese government, and it has also enhanced the importance role of religion in China today.

\section{The Daoist View of their Relationship}

In order to understand the nature of that relationship, it is critical to realize that the interaction between religious-Yin and the Chinese-authority-Yang, especially the concept of turning Yin to Yang and Yang to Yin, does not imply that there is a process of power-shifting between religion and the Chinese authority. Nor does it suggest the possibility of religion, which supersedes the dominant role of the Chinese cult in the near future. Alternatively, a viable interpretation is that through their incessant interaction, the relationship between religion and the Chinese authority gradually becomes closer and inseparable. As a result, they no longer form a one-sided dependent relationship. Instead, they gradually form a reciprocal relationship that encourages and transcends the goodness in religion and government's authority.

\section{The Traditional Approach vs. Daoist Approach}

The traditional and the Daoist approach both focused on the types of relationship between religion and the Chinese government. Nevertheless, the difference between the Daoist approach and the traditional approach is that the Yin-Yang interaction of Taoism recognizes the "soft power" of Yin in religion. The traditional approach focuses more on the mistreatment and the suppression that religion has endured, but fails to recognize the subtle changes that have led the unstoppable growth of religion post the Chinese Cultural Revolution. In fact, the soft power of Yin has allowed religion to continue to expand in China not only by overcoming the obstacles created by the government, but also by gradually gaining more influence and power in other social spheres.

To elaborate more on the impact of Yin-Yang interaction on the development of religion in China, it is important to spend more time on some specific cases of Yin-Yang interaction that have readjusted the relationship between religion and the Chinese government, thus contributing to the contemporary development of religion in China.

\section{The Soft Power of Yin Within Religion}

As a result of limited social resources and rigorously enforced Chinese policies on religion, religious 
institutions that are not state-sanctioned have used the soft power of Yin to their advantage in their interaction with the Chinese authorities. The soft Yin protects them from government harassment and assists their surreptitious development while counterbalancing the strong Yang of government authority. It also encourages them to develop and organize creatively and diversely. Since the 1990s, the Chinese government has attacked the growing numbers of underground Christian churches and unconditionally outlawed the practice of Falun Gong. In response to the suppression and rejection, these religious organizations have remained silent and unnoticed, creating a front of compliance. Nevertheless, if they examine religion in China today, they learn that the diversity of religious institutions in China extends well beyond the simple five state-sanctioned religions. Not only has Christianity become the fastest growing religion in China (Wenger, 2004; Yang, 2004; Vala, 2012), but it has also become the most diversified religious denomination in Chinese society. It is ironic that in an era of religious restriction and limitation, China has become a country with a great diversity of religious beliefs and organizations. One cannot help but wonder what has allowed such religious institutions to expand so rapidly under such repressive conditions.

Fenggang Yang's (2010) triple-colored market theory provides a general explanation of how diverse religious institutions have developed in China. According to the theory, religious institutions are assigned to red, black, and gray markets according to the types of relationships they have with the Chinese authority (p. 25). The red applies to the five state-sanctioned religions. The black market represents the outlawed religious institutions, such as Falun Gong and the Unification Church. The gray market comprises those religions that are not state-sanctioned but neither are they prohibited. Based on the theory, they come to realize that not all religious institutions receive equal support and approval-or disapproval-from the Chinese government, and therefore, these religious institutions develop unevenly.

From a Daoist approach, the colored market a religion belongs to does not entirely affect the development of that religious organization in Chinese society. In fact, successful growth of a religious institution is contingent on the effectiveness of its Yin in countervailing the oppression of Yang. For instance, the common shared traits among "non-state-sanctioned" religions are flexibility and submissiveness of Yin. If these religions can fully utilize their inherited soft power, then they can resist the preemptory control of Chinese state cult in China. Yin's flexibility helps religious organizations to flexibly relocate their meeting locations and reorganize their members into smaller units when facing government invasions and inspections. In addition, the submissiveness of Yin allows religious organizations to perpetuate their existence. The notion of perpetuation for religion is more than simply abiding by the Chinese Constitution and submitting to the control of Chinese authority. It, instead, acts as a mask that strengthens and consolidates the power and existence of religion in Chinese society without confronting the Yang of the Chinese authority directly. If religion engages in direct confrontation with the Chinese cult, it is considered as a foolish act in Taoism. Direct confrontation denotes the failure of Yin-Yang interaction. As they can realize what to expect when two positive or negatively charged magnets face each other, instead of attracting each other, they push each other away. Similarly, a Yang-Yang interaction brings injuries and destruction. In such confrontations, religion often experiences immediate setbacks such as what happened to Falun Gong in the late 1990s. When 10,000 Falun Gong adherents performed a peaceful demonstration near the Zhongnanhai, Beijing, the central government immediately viewed it as a threat to its own legitimacy and quickly crushed it. Nonetheless, the Chinese central government also experienced injuries from this direct confrontation even though it was not apparent at the time. It was criticized by the general public which reduced its image and creditability among the Chinese people, and it 
continued to live with the consequences brought about by its aggression, such as dishonesty and lack of transparency in government.

\section{From "Underground" Churches to "House" Churches}

The expansion of Christianity in China over the past 30 years represents a success story about the interaction between the Yin of religion and the Yang of the Chinese government despite the difficulties that Christian churches have experienced. After the resurgence of religion in the early 1980s, some religious organizations hoped to avoid unexpected suppressions, so they kept their ties with the state-sanctioned religions. Others soon dissociated themselves from the Three-Self Patriotic Movement and the Chinese Patriotic Catholic Association to establish their own units. Their decisions to break away from the state-sanctioned religions implicitly expressed their disapproval of government's infringement on religious practices and beliefs. The Chinese government was worried that their break-away might result in rekindling their relationships with foreign churches for financial support, so the Chinese government appointed SARA in the 1990s to regulate and control the printing and distribution of religious materials and to attack these atomized religious groups by invading their meeting places and arresting their religious leaders.

These "intractable" religious groups were stigmatized as the "underground" churches. They were publicized as evil cults that threatened Chinese people's lives. Due to the government's publicity in the early 1990s, the general public approached these churches with ambivalence and caution. Nevertheless, people's perception of the underground churches began to change when a wave of foreign religions flooded into China during the 1990s. They were organized in small groups at first because they were originally organized by foreigners who were working, studying, or doing business in China. They held their meetings in people's homes. These foreign religious groups were new to China and even though some were Christian denominations, their religious practices and beliefs did not appear compatible with the state-sanctioned Protestantism and Catholicism. Therefore, as outliers they challenged the government's regulations on religion and pressed for reforms. Over the years, their existence as "house churches" began to distinguish them from the stigma of "underground" churches. The term "underground church" continues to hold negative connotations and is usually associated with "evil cults" or "malpractices”. In contrast, the "house” churches began to be viewed as small, state-allowed churches. The growing popularity of new religious groups and foreign churches gradually altered the Chinese government's perception toward the non-state sanctioned religions. The strong Yang of the Chinese state cult was worn down and the Chinese government eventually gave in and reluctantly decided to issue temporary "venues" to some non-state-sanctioned religious organizations. Possessing government temporary "venue", some churches have become semi-state-sanctioned religious institutions, allowed to rent public facilities for religious gatherings.

The diversification in structure and organization of Christian churches is not limited only to the growing number of foreign and local house churches in China today. According to Leung (2003), Christianity is no longer a backward or pastoral religion that is only popular in Chinese countryside. In the past, Christianity was popular among uneducated and poor peasants, women, and seniors in the Chinese countryside; nowadays, it has become a popular religion in the urban areas. It has been organized in accordance with Chinese people's occupations, incomes, residential areas, and ages. Even though public proselytism is illegal according to the Chinese Constitution, many religious believers would sing and hold scripture studies at fast food restaurants and other public places (Yang, 2005). The increasing diversity among religious organizations in China today 
suggests that the soft power of Yin has successfully facilitated growth and protection from the Chinese government's often changing policies on religion. It also affirms that Yin is indeed a powerful force which has diminished the strong Yang of the Chinese state cult without raising its perceptions of danger.

\section{Artificiality, a Daoist No-no}

Throughout Chinese history, the Chinese government's intervention into the development of religion in China has been immeasurable. In the early years of the modern Chinese history, the government took direct and aggressive approach, suppressing and attacking religious manifestation in China. The authoritarian regimes did not recognize "any legal framework protecting social organizations" (Vala, 2012, p. 43). The Chinese government's direct interference with the development of Chinese traditional religions is considered unnatural to the development of religion and unhealthy to its relationship with the religious institutions, and is therefore strongly discouraged. In Taoism, artificiality or contrivance not only disrupts the balance of the Yin-Yang relationship between religion and the Chinese state, but most importantly produces additional consequences (both positive and negative) to the development of religious institutions in contemporary China.

Over recent decades, many religious institutions have developed inconsistently which has directly affected both the positive and negative functions of religion in China. For instance, the government's official announcement banning Falun Gong as an "evil cult" on July 22, 1997 was surprising to both the Chinese public and the international media. Prior to the official ban, Falun Gong was accepted by the Chinese central government at various levels. It was not only perceived as part of the State Sports Administration as a "spiritual movement that combines Buddhist meditation and Taoist Qigong exercises for the objective of promoting physical and mental health” (Ching, 2001, p. 1), but it had also received official recognition as part of Chinese cultural heritage due to its religious and philosophical ties to Buddhist and Taoism.

Even so, it was not recognized as a state-sanctioned religious organization. It lacked the protection of the Chinese Constitution, so it was exposed to public criticisms and attacks. Eventually, conflict broke out which led to the demonstration by 10,000 followers gathered outside the Zhongnanhai, "China's symbolic center of power in Beijing” (Leung, 2002, p. 1). The group expressed its desire to receive official recognition as a state-sanctioned religious organization from the Chinese central government, so that Chinese local and provincial governments would treat them according to standardized procedures (Ching, 2001). Although there were no physical conflicts that led to bloodshed and injuries during the demonstration, it was thought to be the biggest public commotion after the Tiananmen Massacre of 1989. Thus, the Chinese central government thought the Falun Gong's protest at Zhongnanhai was a threat to its political stability. The government became agitated and aggravated the situation by accusing Falun Gong's organizers of inciting their followers to revolt against the legitimacy of the Chinese Communist Party. The direct confrontation of the Yang of Falun Gong and the Yang of Chinese authority led to clashes and confrontations. The stronger side, the Chinese central government, now found valid reasons to tighten its regulation of religious practice and the religious gatherings. The Falun Gong was removed from the public sphere in Chinese society.

Since then, many scandals about the Chinese government's illegal persecutions of Falun Gong's adherents and organizers have been exposed by both the national and international media. Many Chinese people gradually became tired and unsatisfied with the government's illegal methods of dealing with social problems in Chinese society. The Global Attitude Survey of 2012 outlined common fears and doubts among ordinary Chinese people who believed corruption, food safety, unequal growth, scandals, and divorces were threats to China's future due 
to the rapid socio-economic change and modernization (PEW Research Center, 2012). These concerns have remained crucial throughout the years. During the early presidency of the Chinese former president Hu Jintao in 2006, Hu declared a new governmental priority to build a "harmonious society" to resolve social issues needing immediate attention.

Daoism is a promising philosophy. Therefore, an unstable condition in Chinese society is advantageous to the development of religion. For instance, the escalation of divorce rates resulted in infidelity. "According to a survey by Tsinghua University and lifestyle magazine Xiaokang, a total of 2.87 million marriages ended in divorce in 2012, which is a 7.65 percent increase from the previous year”. Many studies have revealed that infidelity is the reason that causes couples' separations in China today (FlorCruz, 2013). Even though the increasing divorce rates cannot be directly associated with the reason that most of the Chinese marriages have a little-to-none affiliation with religious beliefs and practices, there are increasingly more Chinese young couples who are not affiliated to any religious denomination have tied the knot in churches ( $\mathrm{Li}, 2012)$. Getting married at cathedrals or churches has not only become a popular trend among Chinese young couples who still see light and hope in marriage, but it is also an extremely vital mechanism to strengthen the influence of religion by promulgating its beliefs and practices among Chinese young couples and their friends and relatives. Especially, it has helped Christianity to gain greater recognition and support among the Chinese public.

The growing income gap between rich and poor, and increasing corruption that biased job opportunities, imperiled the government's credibility among its citizens. Such issues signal in ethical decline and a growing spiritual vacuum among the Chinese people. In an effort to resolve these issues and restore stability and harmony in their lives, the people seek spiritual nourishment and some turn to religion to deal with the frustrations and pain generated by their daily activities.

Chinese people who seek spiritual growth buttress the existence of Christianity without violating the Article 36 of the Chinese Constitution. It is not only a trend that reflects the impact of the soft power of Yin in religion, but it also proves how the strong Yang of Chinese authority has been abraded through their Yin-Yang interaction. According to Li's interview from China Daily with Fan Guoxing (2012), a pastor at Haidian District Church in Beijing, the Chinese government slackened its religious regulation in 2008, two years after Hu's call for building a "Harmonious Society", so that pastors could hold religious wedding ceremonies for nonbelievers. Pastor Fan has officiated about 40 couples a year, half of which were for nonbelievers.

The increased support Christianity received in Chinese society does not conflict with the Chinese political agenda in building the "Harmonious Society". However, the government perceives the rapid growth of Christianity, a foreign religion, as a threat to its political stability. In order to counteract the increase in Christian faith without attacking Christianity directly, the government argues that since Chinese traditional religions have always been interrelated with the Chinese traditional culture and part of the Chinese cultural heritage, the government is obligated to provide extra supports and approval to enhance the stature of Chinese traditional religions - Confucianism, Daoism, and Buddhism, in order to preserve them (Lim, 2010). As a result, local governments have been actively working with local temples and shrines, providing funding and lands for remodeling existing temples and constructing new ones. According to an article written by reporter Wei (2009) from Xinhua News Agency that the number of official Daoist temples doubled to 3000 in the 14 years from 1995 to 2009, the increasing numbers of Buddhist and Taoist temples have boosted China's tourist economy and also fostered to selective Chinese folklore religions, such as Mazu worshipping. 
Mazu worshipping is a popular folklore religion in southern China including Taiwan. The Chinese government built an emblazoned Mazu temple in Mazu's hometown, Meizhou Island, Fujian Province to accomplish two main purposes. First, constructing Mazu temples was a way for the government to express its support for preserving Chinese traditional culture, and to change people's early view of the Communist Party as an enemy to Chinese folklore religions. Secondly, the government hoped that building Mazu temple in Mazu's hometown would attract more tourists from Taiwan, so that China's political relationship with Taiwan could be strengthened (Lim, 2010).

Although the government's intervention has helped to spread the influence of Chinese traditional religions in contemporary China, most of the positive impact of its involvement has been to preserve them as part of Chinese cultural heritage rather than as religious organizations. For example, the Confucian Peace Award in 2011 was invented by the Chinese government to express its objection to the Nobel Prize committee's decision to award the Nobel Peace Prize of 2011 to Liu Xiaobo. Liu was a Chinese pro-democracy activist who had been sentenced in December, 2009 to prison for 11 years for writing and publishing subversive materials (Metz, 2010). It was not a surprise that the Chinese government would respond quickly to Oslo's decision, but what was shocking to the Chinese people and the rest was the government's decision to revive Taoism as part of Chinese cultural heritage by placing a colossal statue of Confucius in Tiananmen Square. Mao had condemned and disapproved of Confucius and his teachings for "the enduring effects of his feudal practice on the people and, during the Cultural Revolution of 1967 to 1976, Mao called on the Red Guards to destroy all texts, temples, sites, and statues associated with Confucius”. The revival of Confucius, his statue standing at the north gate of the newly renovated National Museum of China on the east side of the Tiananmen Square, almost facing Mao's portrait, was confusing to the Chinese public. People began to question the Party's commitment largely to "all that Mao had stood and fought for" (Gardner, 2011).

Many people have criticized the close relationship the Chinese traditional religions now have with the Chinese government. They are uncomfortable with the idea that these traditional religions are affiliated with and financially supported by the government. The people question the state's devotion to the temples and other sacred sites, especially, when money is heavily involved. Fees are charged at the gates of entrance, and are charged for worship within these sites. As a result, these sites have become less sacred and too touristy. It also appears to some that the amounts of money are willing to pay for worship the Chinese traditional deities now a measure of religious devotion.

Many Chinese people express their contempt for the modernized and marketable Buddhism of recent years, which has turned being monks and nuns into profitable occupations. In order to qualify as a monk or nun, candidates are no longer required to be solely interested in Buddhism as religious practitioners or devout believers, now they also must have college degrees from prestigious universities. These monks are known as “professional monks” (职业和尚). They work at the religious sites every day, and earn a decent monthly income. Additionally, the profession of "monk" has altered the traditional Buddhist forbidding of meat consumptions and the practice of celibacy. Thus, the government's support of traditional religions has fostered irregular and unjust growth, and has created a negative or setback effect on the development of Buddhism and Taoism in comparison to the growth of Christianity in China today.

In turn, Chinese people seeking spiritual enlightenment have found Christianity to be more reliable than the traditional religions. Some reports that pastors or priests of those private churches can be depended upon because their service to God is not money driven, but rather is an expression of their devotion. Believing in 
Christianity is also less expensive than devoting oneself to the Chinese traditional religions, for there is no fee charged every time one enters the cathedrals or churches. Furthermore, Christianity has become a more accessible religion than the other religions due to the growing numbers of the house churches in Chinese residential areas (小区). There is no need to travel far from one's home to be spiritually fed. Thus, Christianity has become a preferred alternative religion.

\section{Conclusion}

It is a common belief in today's world that they can oppose and eliminate much that they strongly oppose to. They are taught to see the world in conflict, and they tend to take "sides" and press for "either/or" decisions. In contrast, Taoism, especially the Yin-Yang principles, allow them to expand our perceptions of the "conflicts" around them. Understanding the multifaceted realities brought into existence by the interaction of Yin and Yang helps them to see the world not as composed of only black or white, strong or weak, right or wrong, but rather that these assumed polarities overlaps and merge into a single reality. As Fowler (2008) asserts,

"Yin and Yang affect all aspects of life, even the temperament of an individual, nature of a society, war, and religion. They make life possible, their interaction creating the relativity necessary for existence. Rest and motion, contradiction and expansion, advance and retreat are the dynamics of the universe” (p. 52-53).

Hence, the dual nature of Yin and Yang offers the contrasting realities which are simultaneously equally important and equally nondescript regardless of whether they are propitious or unfavorable to human desires and expectations. If everything is created through the interaction of Yin-Yang, then nothing exists unconstrained and unrelated to one and the other, despite that the distinct obligation each "part" must fulfill. The Yin-Yang concept suggests that, in order for all existences to sustain and achieve transcendence, they must obtain hseng sheng or "mutually rising". As Billington (1997) explains, "hseng sheng means not just that one cannot exist without the other, but that one is constantly moving towards, and taking the nature of, the other" (p. 111).

The Yin-Yang principles also confirm that relationships between phenomena are not only complementary but also paradoxical and contradictory. The coexistence of both totalitarian and liberal elements in the relationship between religious institutions and the Chinese government reflects the two ongoing realities: the occurring of religious development among the Chinese people and continuing social tension and struggle at the national level. Although the progress of religious freedom in China at the national level may not meet the international standards, they recognize that due to the frequent contact between religious institutions and the Chinese government, churches and other religious groups have achieved a measure of control, recognition, and support in Chinese community level. The development of religion in China has not been consistent or smooth; the relationship between religion and the state has historically been volatile. The vicissitudes of religious freedom in China are similar to the movement of the sea. At one point, it seems inactive, but at other times, it rises and becomes violent. Nevertheless, what is certain is that the relationship between religion and the Chinese government is dynamic and connected. History proved the persistence and the strength of Yin in religion; decades of CCP's suppression on religion did not eradicate its deeply fixed roots in Chinese society. At the turn of the 21st century, China's astonishing economic development has negatively impacted the social fabrics of Chinese society. Chinese society needs or even depends on the support of religious institutions in establishing balance in Chinese society, despite the continued skepticism of the government. Continuing social 
needs and satisfactions will continue to draw religion and the Chinese authority, Yin and Yang, closer to each other in an interdependent relationship.

Obviously, not all relationships between religious institutions and the Chinese government will evolve harmoniously and evenly. There will be sporadic conflicts and some religious institutions may even face elimination as the Yang within them becomes overly dominant and overt. As with the clash of Falun Gong and the central government, when the Yin-impact of Falun Gong had reached its climax and became Yang which exceeded the Chinese government's control, resulting in suppression and coercion in favor of tighter government restriction to retreat that balance (Billington, 1997), so other religions may exceed some of accommodation. But apparently, chaos and destruction are not absolutely negative, they bring new forms of life into existence, and life is an eternal movement: "Eternity is a circle, having neither beginning nor end. Within it, the Yin is constantly moving and changing into the Yang, and the yang into the Yin” (Billington, 1997, p. 113). Thus, the interactions between religion and the Chinese government will continue to vacillate between Yin and Yang, with religion continuing an important, and perhaps increasing, role in Chinese society.

\section{References}

Bell, Catherine. (1989). Religion and Chinese Culture: Towards an Assessment of 'Popular Religion'. History of Religions 29(1):35-57.

Billington, Ray. (1997). Understanding Eastern Philosophy. London, UK: Routledge.

Chen, Ming-Jer. (2002). Transcending paradox: The Chinese 'middle way' perspective. Asian Pacific Journal of Management 19(2/3): 179-99.

Ching, Julie. (2001). The Falun Gong: Religious and political implications. American Asian Review, January 1.

Constitution of the People's Republic of China. (2012) Retrieved from http://english.people.com.cn/constitution/constitution.html

Cooper, Jean C. (2010). An Illustrated Introduction to Taoism: The Wisdom of the Sages. Bloomington, Indiana: World Wisdom Inc.

Eberlein, Xujun. (2008). China: Democracy, or Confucianism? The China Beat, June 3. Retreived from http://thechinabeat.blogspot.com/2008/06/china-democracy-or-confucianism.html

Ebrey, Patricia. (1993). Chinese Civilization: A Sourcebook. 2nd ed. New York: Free Press.

Fang, Tony. (2006). From 'Onion' to 'Ocean': Paradox and Change in National Cultures. International Studies of Management and Organization 35(4):71-90.

Fang, Tony. (2011). Yin Yang: A New Perspective on Culture. Management and Organization Review 8(1):25-50.

FlorCruz, Michelle. (2013). China’s Divorce Rate Rises For Seventh Consecutive Year. IB Times, February 27. Retrieved from http://www.ibtimes.com/chinas-divorce-rate-rises-seventh-consecutive-year-1105053

Fowler, Merv and Jeaneane Fowler. (2008). Chinese Religions: Beliefs and Practices. Brighton, Portland. Sussex Academic Press.

Fritjof, Capra. (1975). The Tao of Physics: an exploration of the parallels between modern physics and eastern mysticism. Boulder: Shambhala. New York: Distributed in the U.S. by Random House.

Gardner, Daniel K. (2011). Mao, Confucius, and Louis Vuitton in Tiananmen Square. ChinaMusings.com. Retrieved from http://chinamusings.com/2011/07/05/mao-confucius-and-louis-vuitton-in-tiananmen-square/

Gentz, Joachim. (2013). Understanding Chinese Religions. London: Dunedin Academic Press Ltd.

He, Na. (2013). Professionals called in to halt rising divorce rate. Chinadaily, March 7. Retrieved from http://www.chinadaily.com.cn/china/2013-03/07/content_16289629.htm

Hong, Ying-yi; Morris, Michael W; Chiu, Chi-yue \& Benet-Martínez, Verónica. (2000). Multicultural minds: A dynamicconstructivist approach to culture and cognition. American Psychologist 55(7): 709-20.

Kuo, Cheng-Tian. (2011). Chinese Religious Reform: The Christian Patriotic Education Campaign. Asian Survey 51(6):1042-64

Lee, Yue-Ting. (2000). What is missing in Chinese-Western dialectical reasoning? American Psychologist 55(9):1065-67.

Lee, Yue-Ting, Ai-guo Han, Tammy K. Byron \& Hong-xia Fan. (2008). Daoist Leadership: Theory and application.(pp. 83-107) in Leadership and Management in China: Philosophies, Theories, and Practices. Edited by C. C. Chen and Y. T. Lee. New York NY: Cambridge University Press. 
Leung, Beatrice. (2002). China and Falun Gong: Party and Society Relations in the Modern Era. Journal of Contemporary China 11(33):761-84a.

Leung, Ka Lun. (2003). Cultural Christians and Christianity in China. The Call of the Sacred. China Rights Forum. No. 4, 2003.

Li-Jun Ji, Richard E. Nisbett \& Yanjie Su. (2001). Culture, change, and prediction. Psychological Science 12(6): 450-56.

Li, Peter Ping. (1998). Towards a geocentric framework of organizational form: A holistic, dynamic and paradoxical approach. Organization Studies 19(5): 829-61.

Li, Peter Ping. (2008).Toward a geocentric framework of trust: An application to organizational trust. Management and Organization Review 4(3): 413-39.

Li, Yao. (2012). More Chinese tie the knot in churches. China Daily, July 22. Retrieved from http://www.thejakartapost.com/news/2012/07/22/more-chinese-tie-knot-churches.html

Lim, Louisa. (2010). China's Leaders Harness Folk Religion For Their Aims. The NPR News, July 23. Retrieved from http://www.npr.org/2010/07/23/128672542/chinas-leaders-harness-folk-religion-for-their-aims

Metz, Jennifer. (2010). Recipient of China’s Confucius Peace Prize Unaware of Award. The ABC News, December 9. Retrieved from http://abcnews.go.com/International/nobel-china-awards-confucius-prize-cracks/story?id=12345833\#.Udm9_UC7J30

Moeller, Hans-Georg. (1893). Philosophy of the Daodejing. New York: Columbia University Press.

Olson, Stuart Alve. (2001). T'ai Chi According to the I Ching: Embodying the principles of the Book of Change. Rochester, Vermont: Inner Traditions.

Peng, Kaiping \& Richard E., Nisbett (1999). Culture, dialectics, and reasoning about contradiction. American Psychologist 54(9): 741-54.

Roth, Harold. (1999). Original Tao: Inward Training (Nei-Yeh) and the Foundations of Taoist Mysticism. New York: Columbia University Press.

The U.S. Department of State. (2011). July-December, 2010 International Religious Freedom Report - China (Includes Tibet, Hong Kong, Macau). Bureau of Democracy, Human Right, and Labor, September, 13. Retrieved from http://www.state.gov/j/drl/rls/irf/2010_5/168351.htm

The U.S. Department of State. (2012). July-December, 2011 International Religious Freedom Report - China (Includes Tibet, Hong Kong, Macau). Bureau of Democracy, Human Right, and Labor, dates unknown. Retrieved from http://www.state.gov/documents/organization/192653.pdf

The U.S. Department of State. (2013). July-December, 2012 International Religious Freedom Report - China (Includes Tibet, Hong Kong, Macau). Bureau of Democracy, Human Right, and Labor, dates unknown. Retrieved from http://www.state.gov/j/drl/rls/irf/religiousfreedom/index.htm\#wrapper

Vala, Carstent T. (2012). Protestant Christianity and Civil Society in Authoritarian China: The Impact of Official Churches and Unregistered “Urban Churches” on Civil Society Development in the 2000s. China's Perspectives 2012(3):43-52.

Wenger, Jacqueline E. (2004). Official vs. Underground Protestant Churches in China: Challenges for Reconciliation and Social Influence. Review of Religious Research 46(2):169-82.

Wei, Wu. (2009). The Great Practice of the Freedom of Religious Belief. A Summary of the 60 Years of Religious Affairs since the Establishment of New China. Xinhua News Agency, September 4. Retrieved from http://news.xinhuanet.com/politics/2009-09/04/content_11997424.htm

Yang, C.K. (1962). Religion in Chinese Society. Berkeley: University of California Press.

Yang, Fenggang. (2004). Between Secularist Ideology and Desecularizing Reality: The Birth and Growth of Religious Research in Communist China. The association for the Sociology of Religion 2004: 101-19.

Yang, Fenggang. (2005). Lost in the Market, Saved at McDonald's: Conversion to Christianity in Urban China. The Scientific Study of Religion 44(4): 423-41.

Yang, Fenggang. (2010). Religion in China: Survival \& Revival under Communist Rule. New York: Oxford University Press. 